\title{
Congenital Ewing's Sarcoma/Primitive Neuroectodermal Tumor of the Upper Extremity
}

\author{
Li Wang, ${ }^{1,2}$ Xibiao Yang, ${ }^{3}$ Zhongcheng Han, ${ }^{4}$ and Chuying Huang ${ }^{2,5,}$ \\ ${ }_{1}^{1}$ Department of Medical Dermatology, Enshi Tujia and Miao Autonomous Prefecture Central Hospital, Enshi, China \\ ${ }_{2}^{2}$ Department of Medical Oncology, West China Hospital of Sichuan University, Chengdu, China \\ 3 Department of Radiology, West China Hospital of Sichuan University, Chengdu, China \\ ${ }_{4}$ Department of Radiology, West China Hospital of Sichuan University, Chengdu, China
Department of Medical Oncology, Xinjiang Uygur Autonomous Region People's Hospital, Xinjiang Uygur Autonomous Region, China \\ ${ }_{5}^{2}$ Department of Medical Oncology, Xinjiang Uygur Autonomous Region People's Hospital, Xinjiang Uygur Auton
${ }^{2}$ Cepart Medical Oncology, Enshi Tujia and Miao Autonomous Prefecture Central Hospital, Enshi, China \\ ${ }^{*}$ Corresponding author: Chuying Huang. Department of Medical Oncology, Enshi Tujia and Miao Autonomous Prefecture Central Hospital, Enshi, China. Tel: +86-2885422683, Fax: \\ +86-2885423278, E-mail: huangjiajiaxiaoyao@yeah.net
}

Received: 2015 August 8; Revised 2015 August 26; Accepted 2015 September 30

Keywords: Congenital ES/PNET, Stem Cell Transplantation, Chemoradiotherapy

\section{Dear Editor,}

The patient was a female newborn, $3200 \mathrm{~g}$ in weight, 50 $\mathrm{Cm}$ in length, who presented at birth with a firm mass on the left upper arm, measuring $25 \times 16 \times 45 \mathrm{~mm}$ in size. Physical examination revealed a non-movable mass with firm consistency and mild tenderness on the left upper arm. Family and maternal histories were unnoteworthy, and the laboratory examination was normal. An excisional biopsy of the mass was performed and the histopathological findings of the excised lesion were ES/PNET. Immunohistochemistry was positive for CD99, NSE, PCK, desmin, and negative for CK. In enhanced chest CT, abdominal ultrasonography, and whole body bone scan no evidence of abnormality or metastasis was detected. Bone marrow biopsy and further treatment were refused by her parents.

Unfortunately, the sarcoma recurred one year later. Seven cycles of VIDE regimen (Vincristine $0.25 \mathrm{mg}$ d1; Ifosfamide 500 mg d1-4; Doxorubicin 3.5 mg d1-4; Teniposide $50 \mathrm{mg} \mathrm{d1}, 25 \mathrm{mg} \mathrm{d} 2-4)$ was administered. After radiation therapy (3040cGy/19 fractions, $6 \mathrm{MeV}$ electrons), the patient underwent autologous stem cell transplantation and achieved a complete remission. Two years later, the patient came to our institution presenting with a subcutaneous mass near the area of surgical scar on the left upper arm. The ultraphonic revealed several hypoechoic nodules between the skin and subcutaneous fat layer on the left upper arm, the biggest one measured $15 \times 5 \mathrm{~mm}$ in size. X-ray (Panel A) showed no adjacent humerus destruction. Magnetic Resonance Imaging showed several nodules on the shallow surface of biceps muscle of the left arm with slight enhancement and marked swelling of the surrounding soft tissue (Panel B, C, arrow). Chest CT scan and whole body bone scan were normal. Subsequent excisional biopsies were performed on 18/11/2013, and the postoperative pathologic results were Ewing's sarcoma. The patient was treated by a course of three-dimensional conformal radiotherapy (3D-CRT) after surgery. Dose of external irradiation was 4680cGy/26 fractions ( $6 \mathrm{MeV}$ Xray) in 30 days. The patient is alive 20 months after the second relapse.

ES and PNET share common antigenic profiles, cytogenic aberrations and proto-oncogene expression which are derived from the same primordial bone marrowderived mesenchymal stem cell (1). At the molecular level, ES/PNET is characterized by chromosomal translocations that fuse the EWSR1 gene to some members of the ETS family of transcription factors, being FLI1 the most frequently implicated [t (11; 22) (q24; q12)] (2). The incidence of these tumors in early childhood is rare, accounting for less than 10 cases per million each year (3), and the incidence in newborns is exceedingly rare. Wong et al reported 1975 patients with Ewing's sarcoma, only 39 (2.0\%) were diagnosed at $<12$ months of age (4). ES/PNET with a slight male predominance occur predominantly in primarily white and Hispanic patients; however, these tumors are extremely rare in individuals of African or Asian origin (2). ES/PNET account for approximately 10\% of primary malignant bone tumors and mainly affect the long bones (47\%), pelvis or ribs (5). While 30\% are seen in an extraskeletal location of the soft tissues, $5 \%$ occurred in extremities among these extraskeletal Ewing's sarcomas $(6,7)$. Manifestation in extraskeletal location of the soft tissues of extremities rarely occurs and this would appear to be the first description of a congenital ES/PNET arising in the soft tissue of upper extremity.

Multiagent systemic therapy for localized ES/PNET

Copyright (c) 2015, Growth \& Development Research Center. This is an open-access article distributed under the terms of the Creative Commons Attribution-NonCommercial 4.0 International License (http://creativecommons.org/licenses/by-nc/4.0/) which permits copy and redistribute the material just in noncommercial usages, provided the original work is properly cited. 
achieved a 5-year survival of approximatly 70 - 75\% (8-10). The similarity in survival between older and younger patients with Ewing sarcoma was reported in literature (11). A study including $2202 \mathrm{ES} /$ PNETs demonstrated that extraskeletal ES/PNETs have a superior prognosis compared with skeletal Ewing sarcoma. About $30-40 \%$ of patients suffer from recurrent tumors and have a very poor prognosis (12). The 5-year survival following recurrence of these patients is approximately $10-15 \%$, while it was $7 \%$ for those whose disease recurred within 2 years (13). In our case of disease recurrence after surgery, the patient was treated with multiagent chemotherapy, stem cell transplantation and aggressive surgical treatment, and is still surviving.

\section{References}

1. Suva ML, Riggi N, Stehle JC, Baumer K, Tercier S, Joseph JM, et al. Identification of cancer stem cells in Ewing's sarcoma. Cancer Res. 2009;69(5):1776-81. doi: 10.1158/0008-5472.CAN-08-2242. [PubMed:19208848]

2. Cidre-Aranaz F, Alonso J. EWS/FLI1 Target Genes and Therapeutic Opportunities in Ewing Sarcoma. Front Oncol. 2015;5:162. doi: 10.3389/fonc.2015.00162. [PubMed: 26258070]

3. Stiller CA, Bielack SS, Jundt G, Steliarova-Foucher E. Bone tumours in European children and adolescents, 1978-1997. Report from the Automated Childhood Cancer Information System project. Eur J Cancer. 2006;42(13):2124-35. doi: 10.1016/j.ejca.2006.05.015. [PubMed:16919776]

4. Wong T, Goldsby RE, Wustrack R, Cash T, Isakoff MS, DuBois SG. Clinical features and outcomes of infants with Ewing sarcoma under 12 months of age. Pediatr Blood Cancer. 2015;62(11):1947-51. doi:10.1002/pbc.25635. [PubMed: 26173989]

5. Yasuda T, Inagaki T, Yamanouchi Y, Kawamoto K, Kohdera U, Kawasaki H, et al. A case of primary Ewing's sarcoma of the occipital bone presenting with obstructive hydrocephalus. Childs Nerv
Syst. 2003;19(12):792-9. doi: 10.1007/s00381-003-0816-z. [PubMed: 14586633]

6. Granowetter L, Womer R, Devidas M, Krailo M, Wang C, Bernstein $\mathrm{M}$, et al. Dose-intensified compared with standard chemotherapy for nonmetastatic Ewing sarcoma family of tumors: a Children's Oncology Group Study. J Clin Oncol. 2009;27(15):2536-41. doi:10.1200/JCO.2008.19.1478. [PubMed: 19349548]

7. Applebaum MA, Worch J, Matthay KK, Goldsby R, Neuhaus J, West DC, et al. Clinical features and outcomes in patients with extraskeletal Ewing sarcoma. Cancer. 2011;117(13):3027-32. doi: 10.1002/cncr.25840. [PubMed: 21692057]

8. Ferrari S, Sundby Hall K, Luksch R, Tienghi A, Wiebe T, Fagioli F, et al. Nonmetastatic Ewing family tumors: high-dose chemotherapy with stem cell rescue in poor responder patients. Results of the Italian Sarcoma Group/Scandinavian Sarcoma Group III protocol. Ann Oncol. 2011;22(5):1221-7. doi: 10.1093/annonc/mdq573. [PubMed: 21059639]

9. Krasin MJ, Davidoff AM, Rodriguez-Galindo C, Billups CA, Fuller $\mathrm{CE}$, Neel MD, et al. Definitive surgery and multiagent systemic therapy for patients with localized Ewing sarcoma family of tumors: local outcome and prognostic factors. Cancer. 2005;104(2):367-73. doi:10.1002/cncr.21160. [PubMed: 15948159]

10. De Ioris MA, Prete A, Cozza R, Podda M, Manzitti C, Pession A, et al. Ewing sarcoma of the bone in children under 6 years of age. PLoS One. 2013;8(1):e53223. doi: 10.1371/journal.pone.0053223. [PubMed: 23382839]

11. Duchman KR, Gao Y, Miller BJ. Prognostic factors for survival in patients with Ewing's sarcoma using the surveillance, epidemiology, and end results (SEER) program database. Cancer Epidemiol. 2015;39(2):189-95. doi:10.1016/j.canep.2014.12.012. [PubMed: 25595632]

12. Jurgens H, Exner U, Gadner H, Harms D, Michaelis J, Sauer R, et al. Multidisciplinary treatment of primary Ewing's sarcoma of bone. A 6-year experience of a European Cooperative Trial. Cancer. 1988;61(1):23-32. [PubMed: 3334950]

13. Leavey PJ, Mascarenhas L, Marina N, Chen Z, Krailo M, Miser J, et al. Prognostic factors for patients with Ewing sarcoma (EWS) at first recurrence following multi-modality therapy: A report from the Children's Oncology Group. Pediatr Blood Cancer. 2008;51(3):3348. doi:10.1002/pbc.21618. [PubMed:18506764] 